\title{
Underweight, overweight, and tobacco use among adolescents aged 12-15 years: Evidence from 23 low-income and middle-income countries
}

\author{
Qian Wang
}

\begin{abstract}
INTRODUCTION Compared with the number of studies in adults, body weight in relation to tobacco use has been understudied in the adolescent population. This study aimed to examine the association between underweight, overweight and tobacco use in low- and middle-income countries.

METHOdS Data were derived from the Global School-Based Student Health Survey (GSHS). Data from 71176 adolescents aged 12-15 years residing in 23 countries were analyzed. The Centers for Disease Control and Prevention (CDC) 2000 growth charts were used to identify underweight, normal weight, and overweight/ obesity. Weighted age- and gender-adjusted prevalence of weight categories and tobacco use was calculated. Multivariate logistic regression analysis was performed to estimate the association between weight categories and tobacco use for each country, controlling for covariates. Pooled odds ratios and confidence intervals were computed using random- or fixed-effects meta-analyses.

RESULTS A significant association between weight categories and tobacco use was evident in only a few countries. Adolescents reporting tobacco use in French Polynesia, Suriname, and Indonesia, had 72\% (95\% CI: 0.15-0.56), 55\% (95\% CI: 0.24-0.84), and 24\% (95\% CI: 0.61-0.94) lower odds of being underweight, respectively. Adolescents reporting tobacco use in Uganda, Algeria, and Namibia, had 2.30 (95\% CI: 1.04-5.09), 1.71 (95\% CI: 1.25-2.34), and 1.45 (95\% CI: 1.00-2.12) times greater odds of being overweight/obese, but those in Indonesia and Malaysia had 33\% (95\% CI: 0.50-0.91) and 16\% (95\% CI: $0.73-0.98)$ lower odds of being overweight/obese.

CONCLUSIONS The association between tobacco use and BMI categories is likely to be different among adolescents versus adults. Associating tobacco use with being thin may be more myth than fact and should be emphasized in tobacco prevention programs targeting adolescents.
\end{abstract}

\author{
AFFILIATION \\ 1 School of Public Health, \\ Shanghai Jiao Tong University \\ School of Medicine, Shanghai, \\ China \\ CORRESPONDENCE TO \\ Qian Wang. School of Public \\ Health, Shanghai Jiao Tong \\ University School of Medicine, \\ 227 S Chongqing Rd, \\ Huangpu District, Shanghai \\ 200025, China. E-mail: qian. \\ wang@shsmu.edu.cn \\ ORCID ID: https://orcid. \\ org/0000-0002-4713-5557
}

\section{KEYWORDS}

underweight, overweight, tobacco use, adolescents, low- and middle-income countries

Received: 28 November 2020 Revised: 8 February 2021 Accepted: 3 March 2021

\section{INTRODUCTION}

Tobacco use has long been recognized as a leading risk factor for non-communicable diseases ${ }^{1}$. Since the World Health Organization's Framework Convention on Tobacco Control (FCTC) came into effect in 2005, many high-income countries (HICs) legislated the majority of WHO policies for tobacco control, and smoking prevalence continued to decline in these countries ${ }^{2,3}$. Although middle-income countries also increased the number of legislated tobacco control policies during this time, yet, upper middle-income countries are now estimated to have the highest smoking prevalence $(24 \%)^{2,3}$. Low-income countries lagged behind both the high-income and middleincome countries in the speed and scope of tobaccocontrol policy legislation ${ }^{3}$, and over a third of low- 
income countries had insufficient national data to consistently document trends in smoking prevalence ${ }^{2}$. Moreover, compared with high-income countries, low- and middle-income countries are increasingly burdened by tobacco use related mortalities ${ }^{4}$. As a result, tobacco use is increasingly becoming a looming public health challenge threatening low- and middleincome countries.

The association between body weight and tobacco use, especially cigarette smoking in the adult population has been the focus of numerous studies. Nicotine, the chief addictive substance in tobacco products, can contribute to weight loss by reducing appetite and increasing energy expenditure ${ }^{5}$. In the adult population, cross-sectional and longitudinal studies appear to support an inverse relationship between cigarette smoking and body weight, as prolonged consumption of nicotine was associated with increased central adiposity ${ }^{6}$. Compared with adulthood, adolescence is characterized by experimental use of all forms of tobacco products, and concerns about being overweight or obese are often cited as a reason for smoking initiation among adolescents $^{6,7}$. Some studies have proposed that young people may perceive smoking as a weight control method; overweight/obese youth may perceive smoking as a method of self-medication to relieve weight-associated psychological distress; and smoking can also be perceived as a means to build social relationships with others, especially by overweight/ obese adolescents experiencing weight-related social isolation ${ }^{8}$. However, contrary to the popular belief, there is insufficient evidence suggesting that smoking is associated with significant weight loss among adolescents and young adults ${ }^{9,10}$, perhaps because the weight-reducing effect of nicotine consumption is accumulated over time, only becoming significantly evident in adulthood ${ }^{10}$.

Studies supporting these findings were mainly conducted among adolescents in western countries, the association between body weight and cigarette smoking among adolescents in low- and middleincome countries has been underexplored. Therefore, this study aimed to draw attention to this issue by utilizing the Global School-based Student Health Survey (GSHS), which collects data from adolescents in a large number of low- and middle-income countries. The GSHS is one of the very few surveys that collect information on health-related behaviors of adolescents residing in countries where national surveillance systems are not yet established. It was argued that patterns of tobacco use should be assessed within the unique social and cultural contexts ${ }^{11}$. Unlike in western countries where cigarette smoking is the predominant form of tobacco use, use of non-cigarette tobacco products is the culturally predominant form of tobacco consumption in many low- and middle-income countries ${ }^{12}$. Thus, the key independent variable in this study was tobacco use, including cigarettes, as well as other nicotinecontaining tobacco products.

Body weight can be represented by the body mass index (BMI, $\mathrm{kg} / \mathrm{m}^{2}$ ). BMI has become the most practical, inexpensive, and non-invasive anthropometric measure ${ }^{13}$, especially in populationbased surveys where direct measures of body weight and height were not feasible. It was found to correlate well with objectively measured body weight and height, body fat and cardiovascular risk factors in children and adolescents ${ }^{14-16}$. BMI values for children and adolescents aged $<19$ years are usually adjusted for age and gender, and expressed as a percentile showing the relative position of a child's or an adolescent's weight and height among peers of the same gender and age. For the adolescent population, two of the most commonly referenced BMI-for-age growth charts are the 2000 Centers for Disease Control and Prevention (CDC) growth charts and the 2007 growth charts (5-19 years) from the World Health Organization (WHO) ${ }^{17,18}$. Both charts were created based on the 1977 growth charts developed by the US National Center for Health Statistics (NCHS). However, the reference population as well as the statistical methods used to construct the two growth charts differed. The 2000 CDC growth charts were constructed based on updated reference population used to create the 1977 NCHS growth charts $^{17}$, whereas the 2007 WHO growth charts (5-19 years) were constructed based on merging the same reference population used in creating the 1977 NCHS growth charts with the 2006 WHO Child Growth Standards for under-fives ${ }^{18}$. In regard to statistical methods, the z-scores in the 1977 NCHS growth charts were based on a fixed standard deviation value above and below the median, whereas the 2000 CDC growth charts were based on the LMS (lambda-mu-sigma) 
smoothing method allowing for a changing standard deviation ${ }^{17}$. For children aged $<5$ years, the 2006 WHO Child Growth Standards were recommended for use ${ }^{19}$; there is also evidence supporting using the 2006 WHO Child Growth Standards over the 2000 CDC growth charts in developing countries ${ }^{20,21}$. However, for youth aged 5-19 years, despite several studies found that the 2007 WHO growth chart (5-19) overestimated obesity prevalence or underestimated stunting prevalence ${ }^{22-24}$, there is almost no evidence endorsing the use of one growth chart over the other. Because the 2000 CDC growth charts were based on more contemporary data and statistical procedures, they were used to derive BMI-for-age percentiles for adolescents aged 12-15 years in the current study. Findings of this study may enhance our collective understanding of the body-weight-tobacco-use link among adolescents worldwide.

\section{METHODS}

\section{Sample}

Data were derived from the Global School-based Student Health Survey (GSHS). The GSHS was developed by the World Health Organization in conjunction with United Nations-affiliated organizations, as well as the United States Centers for Disease Control and Prevention (CDC). It primarily surveys adolescents aged 13-17 years residing in lowor middle-income countries. In each participating country, ethical approval was obtained from the Ministry of Education or a relevant institution ethics review committee. A two-stage cluster sampling design was utilized to obtain nationally representative samples, where schools were first selected with probability proportional to enrollment size, classes within selected schools were randomly chosen during the second stage, and all students in the selected classes were eligible to participate. Verbal or written consents were obtained from participants and their guardians before beginning of the survey. More details about the GSHS can be found elsewhere (https://www.cdc.gov/gshs/pdf/GSHSOVerview. pdf). The target population of the present study was adolescents aged $12-15$ years.

\section{Measures}

Body mass index (BMI) categories - outcome variable Prior to survey administration, survey staff typically measured participants' weight and height and wrote the numbers on paper for students to enter during survey administration ${ }^{25}$. BMI was calculated as weight $(\mathrm{kg})$ divided by height squared $\left(\mathrm{m}^{2}\right)\left(\mathrm{kg} / \mathrm{m}^{2}\right)$. The 2000 CDC growth charts were used to derive ageand gender-adjusted BMI percentiles ${ }^{17}$. According to the growth charts, underweight was defined as a BMI score $<5$ th percentile, normal weight was defined as a BMI score $\geq 5$ th percentile to $<85$ th percentile, overweight was defined as a BMI score $\geq 85$ th percentile, and obese were defined as a BMI score $\geq 95$ th percentile ${ }^{17}$. Participants in the normal weight category were used as the reference group in the multivariate analyses. Because the percentage of adolescents who were obese was low, those who were obese were not categorized separately from those who were overweight. BMI was analyzed as a categorical variable in the current study to help identify those with abnormal weight status and opportunities for interventions.

\section{Tobacco use - exposure variable}

Tobacco use was assessed by the combined responses to two questions: 'During the past 30 days, on how many days did you smoke cigarettes?' and 'During the past 30 days, on how many days did you use any tobacco products other than cigarettes, such as a pipe, rolled tobacco leaves, snuff, or chewing tobacco?'. Response options included: $0,1-2,3-5$, $6-9,10-19,20-29$, and 30 days. Because the majority of participating adolescents reported non-use during the past 30 days, thus skewing the distribution of the variable, responses were dichotomized to distinguish those (tobacco users) reporting at least 1 or 2 days to either question from those reporting non-use to both questions. This was done consistently with other studies $^{26,27}$, moreover, the dichotomized variable was also embedded in the original GSHS datasets as 'Percentage of students who currently used any tobacco product (on at least 1 day during the 30 days before the survey)'.

\section{Covariates}

Variables commonly associated with BMI were included as covariates: age $(12,13,14$, and 15 years $)$, gender (male vs female), food insecurity (used as a proxy measure of socioeconomic status) were assessed by the frequency of going hungry 'because there was 
not enough food in your home' ('most of the time' or 'always' vs 'never', 'rarely', 'sometimes'), fruit and vegetable consumption ( $\geq 5$ times per day vs $<5$ times per day) was assessed by summing the number of times of having fruits or vegetables per day during the past 30 days (used as a proxy for adequate daily intake recommended by the WHO ${ }^{28}$, physical activity was assessed by the number of days physically active for at least $60 \mathrm{~min}$ per day during the past week $(\geq 5$ days/week vs $<5$ days/week).

\section{Data analysis}

Exclusion criteria were: 1) countries that did not include all variables used in this analysis were excluded; and 2) countries that had more than $14 \%$ of data missing on all variables used in the analysis ${ }^{29,30}$. For final analysis, 23 countries were included and grouped by World Bank income level in the corresponding survey year into: low-income countries $(n=3)$, lower middle-income countries $(n=9)$, upper middle-income countries $(n=6)$, and high-income countries $(n=5)$. Only the latest survey was used if a country conducted the GSHS twice or more.

Survey analysis procedures (SAS version 9.4, SAS Institute, Cary, NC) were utilized to account for the complex sampling design of the GSHS. According to the CDC growth charts, age- and gender-adjusted mean BMI percentiles were calculated for each country, and BMI categories were derived from calculated BMI percentiles. Age- and gender-adjusted percentages were also calculated for all other categorical variables. Within each country, the association between BMI categories and tobacco use was estimated via multivariate logistic regression. The pooled total and regional association between BMI categories and tobacco use was estimated via meta-analysis in Stata version 15.1 (StataCorp LLC, Texas, USA), with Higgins' $\mathrm{I}^{2}$ as the indicator of between-country heterogeneity. Between-country heterogeneity is typically considered low when Higgins' $\mathrm{I}^{2}$ is $25 \%-50 \%{ }^{31}$. Because there was significant heterogeneity between countries, a random-effects model was constructed to obtain the pooled estimate of the association. The level of statistical significance was set at $\mathrm{p}<0.05$.

\section{RESULTS}

\section{Sample characteristics}

The sample consisted of 71176 adolescents aged $12-$
15 years residing in 23 countries (Table 1 ). Eighteen countries $(78.3 \%)$ were in the low- to middle-income categories, and 5 countries $(21.7 \%)$ were in the highincome category (Table 1). Age- and gender-adjusted mean BMI percentiles ranged from $36.2 \%(\mathrm{SE}=1.9)$ in Namibia to $80.1 \%(\mathrm{SE}=0.6)$ in Tonga (Table 2$)$. Prevalence of underweight (BMI $<5$ th percentile) ranged from $0.6 \%$ (95\% CI: $0.3-0.8$ ) in Tonga to 17.9\% (95\% CI: 14.4-21.4) in Namibia (Table 2). Prevalence of overweight (BMI $\geq 85$ th percentile) ranged from $6.1 \%$ (95\% CI: 4.8-7.4) in Pakistan to $57.8 \%$ (95\% CI: 55.2-60.4) in Tonga (Table 2). Ageand gender-adjusted prevalence of tobacco use also

Table 1. Survey characteristics by country, Global School-based Student Health Survey 2003-2017 $(\mathrm{N}=71176)$

\begin{tabular}{|c|c|c|c|c|c|}
\hline $\begin{array}{l}\text { Income } \\
\text { level a }^{\text {a }}\end{array}$ & Country & $\begin{array}{c}\text { Survey } \\
\text { year }\end{array}$ & $\begin{array}{l}\text { World } \\
\text { region }\end{array}$ & $\begin{array}{l}\text { Response } \\
\text { rate }(\%)^{b}\end{array}$ & $\begin{array}{l}\text { Sample } \\
\text { size }(n)\end{array}$ \\
\hline \multirow[t]{3}{*}{ LIC } & Benin & 2016 & AFR & 78 & 664 \\
\hline & Uganda & 2003 & AFR & 69 & 1697 \\
\hline & Syria & 2011 & EMR & 97 & 2715 \\
\hline \multirow[t]{9}{*}{ LMIC } & Algeria & 2011 & AFR & 98 & 3275 \\
\hline & $\begin{array}{l}\text { China } \\
\text { (Beijing) }\end{array}$ & 2003 & ASIA & 99 & 1966 \\
\hline & Pakistan & 2009 & ASIA & 76 & 4624 \\
\hline & Indonesia & 2015 & ASIA & 94 & 7941 \\
\hline & Mongolia & 2013 & ASIA & 88 & 3497 \\
\hline & Thailand & 2015 & ASIA & 89 & 3656 \\
\hline & Bolivia & 2012 & AME & 88 & 2562 \\
\hline & Guyana & 2009 & AME & 76 & 1775 \\
\hline & Honduras & 2012 & AME & 79 & 1350 \\
\hline \multirow[t]{6}{*}{ UMIC } & Namibia & 2013 & AFR & 89 & 1693 \\
\hline & Iraq & 2012 & ASIA & 88 & 1370 \\
\hline & Malaysia & 2012 & ASIA & 89 & 15419 \\
\hline & Tonga & 2017 & ASIA & 90 & 1848 \\
\hline & Jamaica & 2017 & AME & 60 & 927 \\
\hline & Suriname & 2016 & AME & 83 & 1374 \\
\hline \multirow[t]{5}{*}{ HIC } & Bahrain & 2016 & ASIA & 89 & 5085 \\
\hline & Brunei & 2014 & ASIA & 65 & 1726 \\
\hline & $\begin{array}{l}\text { French } \\
\text { Polynesia }\end{array}$ & 2015 & AME & 70 & 1726 \\
\hline & Mauritius & 2017 & AFR & 84 & 1790 \\
\hline & Uruguay & 2012 & AME & 77 & 2496 \\
\hline
\end{tabular}

LIC: low-income countries. LMIC: lower middle-income countries. UMIC: upper middle-income countries. HIC: high income countries. AFR: African region. AMR: Region of the Americas. EMR: Eastern Mediterranean Region. a Country income level was based on the World Bank classification at the year of the survey in the respective countries. $b$ Response rate: school response rate $\times$ student response rate. c Students aged $12-15$ years. 
varied across countries, ranging from 1.1\% (95\% CI: $0.3-1.9$ ) in Benin to $14.8 \%$ (95\% CI: $11.7-17.9)$ in Syria (Table 2).

Food insecurity was highest in Syria (10.1\%; 95\% CI: 7.7-12.5) and lowest in Mongolia (1.0\%; 95\% CI: 0.5-1.4) (Supplementary file Table S1). More than half of respondents in 19 countries reported consuming fruits and vegetables for $\geq 5$ times per day, with the highest percentage of consumption (90.6\%; 95\% CI: 89.3-92.0) observed in Beijing, China. Fruit and vegetable consumption was lowest among adolescents aged 12-15 years in Benin (19.9\%; 95\% CI: 18.6-21.1) (Supplementary Table S1). More than $40 \%$ of respondents in Uruguay were physically active for at least 60 minutes for $\geq 5$ days within the past week; in comparison, only $8.0 \%$ of respondents did the same in Namibia (Supplementary Table S1).

\section{BMI categories and tobacco use}

The association between underweight and tobacco use did not reach statistical significance in The majority of the countries examined (Figure 1). A negative association was evident in only 3 countries: French Polynesia, Suriname, and Indonesia (Figure $1)$. Respondents engaging in tobacco use in French Polynesia were $72 \%$ (95\% CI: 0.15-0.56) less likely to be underweight (Figure 1). Respondents in Suriname that engaged in tobacco use were 55\% (95\% CI: 0.24-

Table 2. Age- and gender-adjusted prevalence of BMI categories and tobacco use among adolescents aged 12-15 years in 23 countries, Global School-Based Student Health Survey 2003-2017 (N=71176)

\begin{tabular}{|c|c|c|c|c|c|c|}
\hline \multirow{3}{*}{$\begin{array}{l}\text { Income } \\
\text { level }^{\text {a }}\end{array}$} & \multirow[t]{3}{*}{ Country } & \multicolumn{4}{|c|}{$B M I^{b, c}$} & \multirow[t]{2}{*}{ Tobacco use ${ }^{c .}$} \\
\hline & & \multirow{2}{*}{$\begin{array}{c}\text { Mean } \\
\text { percentile } \\
\text { (S.E.) }\end{array}$} & $<5$ th percentile & $\begin{array}{c}5 \text { th to }<85 \text { th } \\
\text { percentile }\end{array}$ & $\geq 85$ th percentile & \\
\hline & & & $\%(95 \% \mathrm{CI})$ & $\%(95 \% \mathrm{CI})$ & $\%(95 \% \mathrm{CI})$ & $\%(95 \%$ CI $)$ \\
\hline \multirow[t]{3}{*}{ LIC } & Benin & $46.7(2.6)$ & $10.6(7.5-13.8)$ & $74.3(68.8-79.7)$ & 15.1 (9.3-20.9) & $1.1(0.3-1.9)$ \\
\hline & Uganda & $42.1(2.5)$ & $12.1(7.6-16.7)$ & $80.9(76.4-85.3)$ & $7.0(4.0-10.0)$ & $1.7(0.2-3.2)$ \\
\hline & Syria & $58.0(1.2)$ & $5.2(4.1-6.4)$ & $72.8(70.3-75.2)$ & $22.0(19.0-25.0)$ & $14.8(11.7-17.9)$ \\
\hline \multirow[t]{9}{*}{ LMIC } & Algeria & $46.1(1.1)$ & $8.5(7.3-9.7)$ & $77.4(75.5-79.4)$ & $14.1(12.0-16.1)$ & $4.7(3.6-5.9)$ \\
\hline & China (Beijing) & $51.8(1.5)$ & $6.8(5.6-8.0)$ & $72.1(68.0-76.3)$ & $21.1(17.0-25.2)$ & $4.0(2.4-5.6)$ \\
\hline & Pakistan & $36.7(1.2)$ & $14.2(11.6-16.8)$ & $79.7(77.4-82.0)$ & $6.1(4.8-7.4)$ & 7.5 (5.2-9.7) \\
\hline & Indonesia & $47.0(0.9)$ & $10.9(9.8-12.1)$ & $71.3(69.5-73.2)$ & 17.7 (15.7-19.8) & $7.3(5.5-9.0)$ \\
\hline & Mongolia & $48.7(0.8)$ & $4.2(3.5-5.0)$ & $83.9(82.4-85.4)$ & $11.9(10.2-13.6)$ & $3.3(2.5-4.2)$ \\
\hline & Thailand & $51.3(1.0)$ & $9.3(8.1-10.6)$ & $67.2(64.5-69.9)$ & $23.5(20.6-26.3)$ & $7.4(5.3-9.4)$ \\
\hline & Bolivia & $61.3(0.9)$ & $1.7(1.2-2.1)$ & $75.3(72.6-78.0)$ & $23.0(20.2-25.8)$ & $7.2(4.9-9.5)$ \\
\hline & Guyana & $49.1(1.6)$ & $9.6(6.9-12.3)$ & $72.5(68.5-76.5)$ & $17.9(14.6-21.2)$ & $11.3(2.6-19.9)$ \\
\hline & Honduras & $54.5(1.2)$ & $4.1(2.8-5.3)$ & $74.6(70.6-78.5)$ & $21.4(17.4-25.4)$ & $8.7(5.6-11.8)$ \\
\hline \multirow[t]{6}{*}{ UMIC } & Namibia & $36.2(1.9)$ & $17.9(14.4-21.4)$ & $73.6(70.5-76.7)$ & $8.5(5.1-12.0)$ & $2.2(1.2-3.2)$ \\
\hline & Iraq & $57.9(1.4)$ & $5.8(4.3-7.4)$ & $66.4(63.3-69.6)$ & $27.8(24.0-31.5)$ & $4.7(3.2-6.2)$ \\
\hline & Malaysia & $54.6(0.3)$ & $9.8(9.3-10.2)$ & $60.6(59.5-61.7)$ & $29.7(28.7-30.6)$ & $3.1(2.5-3.8)$ \\
\hline & Tonga & $80.1(0.6)$ & $0.6(0.3-0.8)$ & $41.7(39.1-44.2)$ & $57.8(55.2-60.4)$ & $9.1(6.9-11.3)$ \\
\hline & Jamaica & $59.9(1.2)$ & $4.0(2.7-5.4)$ & $67.9(64.5-71.4)$ & $28.0(24.9-31.1)$ & $9.5(2.6-16.3)$ \\
\hline & Suriname & $59.5(0.6)$ & $7.5(6.3-8.7)$ & $61.1(57.9-64.4)$ & $31.1(28.5-34.1)$ & $3.9(2.3-5.4)$ \\
\hline \multirow[t]{5}{*}{ HIC } & Bahrain & $68.8(0.6)$ & $4.6(3.9-5.4)$ & $49.9(48.5-51.4)$ & $45.4(43.8-47.0)$ & $6.4(5.1-7.7)$ \\
\hline & Brunei & $68.0(0.9)$ & $3.3(2.6-4.0)$ & $53.7(50.6-56.9)$ & $43.0(39.7-46.2)$ & $3.5(2.5-4.6)$ \\
\hline & French Polynesia & $73.6(1.4)$ & $1.2(0.3-2.1)$ & $50.9(46.8-55.0)$ & $47.9(43.5-52.4)$ & $8.6(6.3-10.8)$ \\
\hline & Mauritius & $54.4(1.1)$ & $13.8(12.2-15.4)$ & $55.0(51.5-58.5)$ & $31.2(28.0-34.5)$ & $4.8(3.2-6.3)$ \\
\hline & Uruguay & $62.8(0.7)$ & $2.3(1.7-2.8)$ & $69.3(66.4-72.2)$ & $28.4(25.6-31.2)$ & $3.3(1.7-4.8)$ \\
\hline
\end{tabular}

LIC: Iow-income countries. LMIC: lower middle-income countries. UMIC: upper middle-income countries. HIC: high income countries. a Country income level was based on the World Bank classification at the year of the survey in the respective countries. b BMI percentiles were calculated based on the Centers for Disease Control and Prevention 2000 growth charts. c Estimates were weighted and adjusted for age and gender. d Past 30-day use of cigarettes and other tobacco products. 
Figure 1. Country-wise association between past 30-day any tobacco use and being underweight estimated by multivariate logistic regression

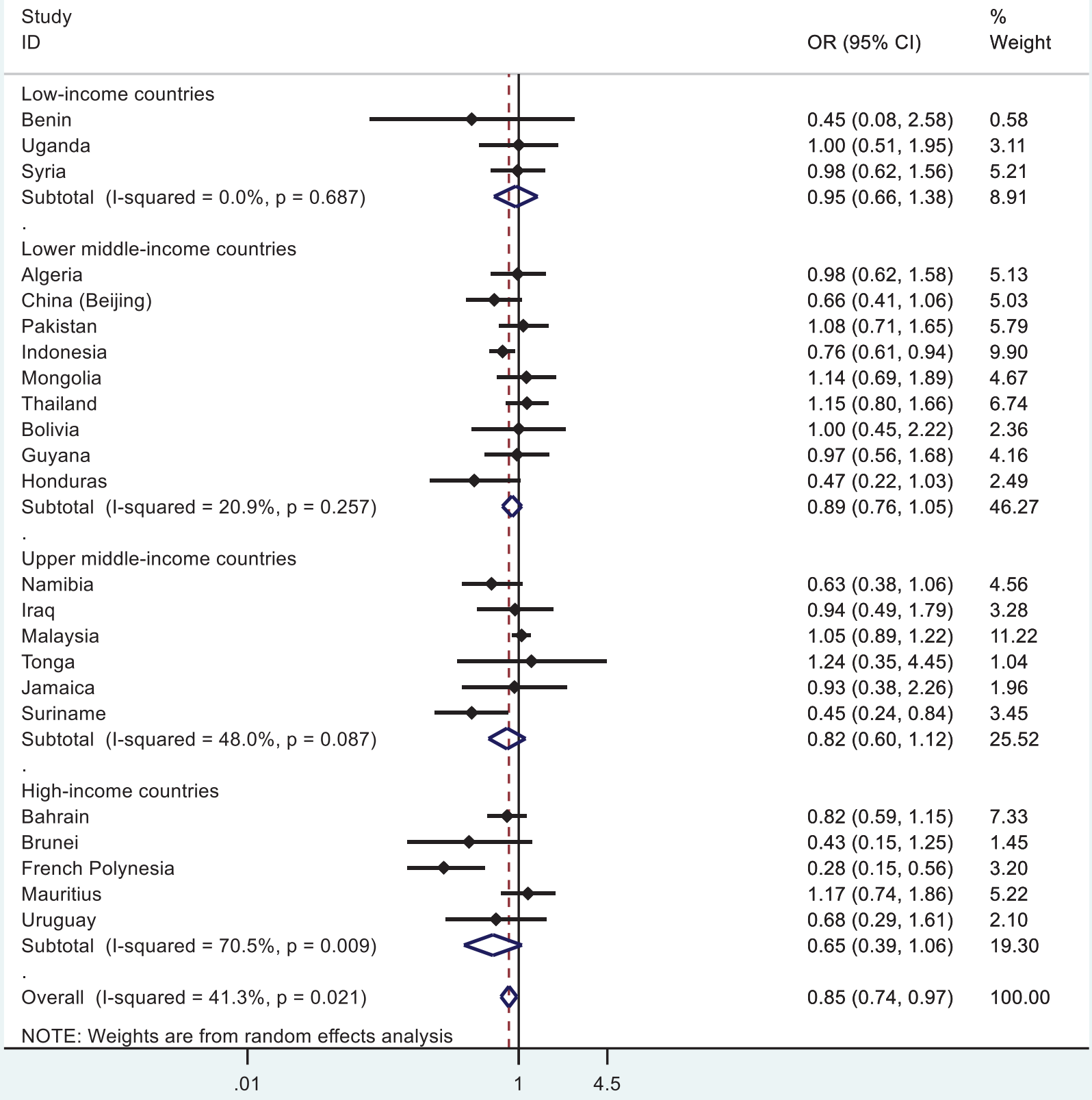

OR: odds ratio. $\mathrm{Cl}$ : confidence interval. Within each country, the multivariate model was adjusted for age, gender, food insecurity, fruit and vegetable consumption, and past 7-day physical activity frequency. Pooled estimates were obtained by random-effects meta-analysis.

0.84 ) less likely to be underweight (Figure 1). And those engaging in tobacco use in Indonesia were $24 \%$ (95\% CI: 0.61-0.94) less likely to be underweight (Figure 1).

Similarly, the association between overweight/ obesity and tobacco use did not reach statistical significance in the majority of the countries examined (Figure 2). A positive association was observed in Uganda, Algeria, and Namibia (Figure 2). In contrast, a negative association was observed in Indonesia 
Figure 2. Country-wise association between past 30-day any tobacco use and being overweight/obese estimated by multivariate logistic regression

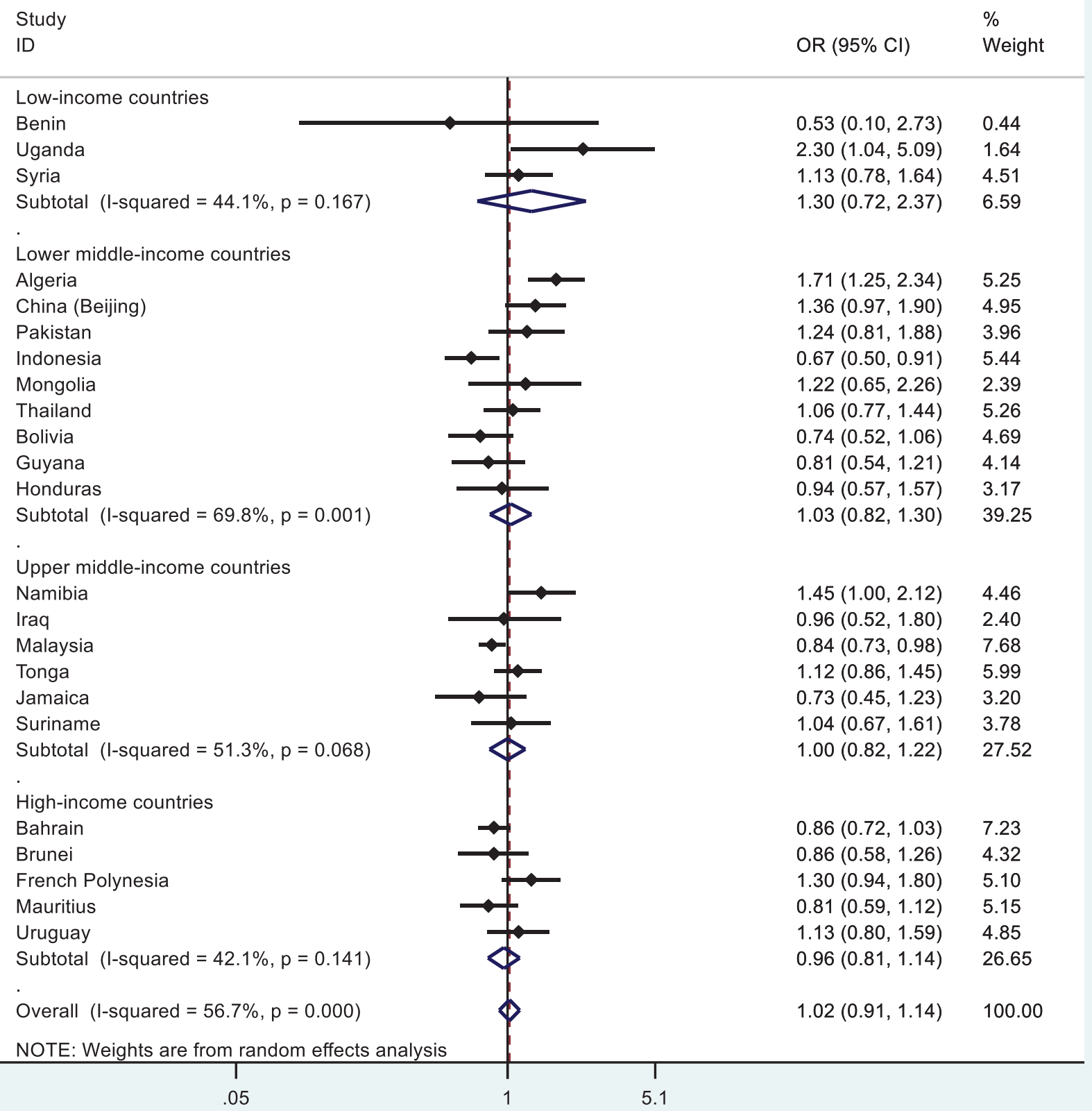

OR: odds ratio. Cl: confidence interval. Within each country, the multivariate model was adjusted for age, gender, food insecurity, fruit and vegetable consumption, and past 7-day physical activity frequency. Pooled estimates were obtained by random-effects meta-analysis.

and Malaysia (Figure 2). In Uganda, Algeria, and Namibia, respondents engaging in tobacco use had 2.30 (95\% CI: 1.04-5.09), 1.71 (95\% CI: 1.25-2.34), and 1.45 (95\% CI: $1.00-2.12)$ times greater odds to be overweight/obese, respectively; while respondents in Indonesia and Malaysia were 33\% (95\% CI: 0.50$0.91)$ and $16 \%$ (95\% CI: 0.73-0.98) less likely to be overweight/obese, respectively (Figure 2). 


\section{DISCUSSION}

This was the first study to examine the association of BMI categories with tobacco use among nationally representative samples of adolescents aged 12-15 years residing mainly in low-income and middleincome countries. Existing studies on this association were commonly conducted in western industrialized nations where smoking rates have declined but obesity rates have increased. Overall, the findings point to considerable between-country heterogeneities in the prevalence as well as association of BMI categories and tobacco use.

In six countries (Namibia, Pakistan, Mauritius, Uganda, Benin, and Indonesia), more than $10 \%$ of adolescents were underweight, and 4 out of the 6 countries were in the low-income or lower middleincome category. Namibia and Pakistan reported the highest prevalence of underweight adolescents $(17.9 \% ; 14.2 \%)$, but a comparatively low prevalence of overweight/obese adolescents $(8.5 \% ; 6.1 \%)$. There has been ample evidence documenting underweight among children under the age of five in Namibia, but limited coverage on its adolescent population. Similarly, both stunting and wasting remain heavily prevalent among children under the age of five in Pakistan. In fact, Pakistan has the second highest infant and child mortality rate in South Asia, with undernutrition as a major contributor ${ }^{32}$. The reasons for such conditions in Pakistan are multidimensional, including congenital abnormalities, maternal undernutrition and early cessation of breastfeeding, gender and income inequality, sanitation related to food preparation, and other sociocultural factors ${ }^{32}$. Underweight and stunting has been extensively documented among children and adolescents aged $<16$ years in Uganda ${ }^{33-35}$. Adolescents aged 12-15 years in Mauritius were found to exhibit the third highest prevalence of underweight, and the sixth highest prevalence of overweight/obesity among all 23 countries. In another study, a high prevalence of both overweight and thinness was also observed among children aged 9-10 years in Mauritius ${ }^{36}$. Similarly, the comparable prevalence of underweight and overweight/obesity observed among adolescents aged 12-15 years in Benin and Indonesia was consistent with the existing literature ${ }^{37,38}$. This pattern of the dual burden of malnutrition seen in children and adolescents may pose unique public health challenges in these countries.

On the other hand, in four countries (Tonga, French Polynesia, Bahrain, and Brunei), more than $40 \%$ of responding adolescents aged $12-15$ years were overweight/obese, and 3 out of the 4 countries were in the high-income category. Tonga, an upper middle-income country, had more than half $(57.8 \%)$ of respondents identified as overweight or obese. These four countries also had a comparatively low underweight prevalence $(0.6 \%-4.6 \%)$. Both Tonga and French Polynesia belong to an archipelago of island countries scattered across the Pacific Ocean. The WHO estimated that at least ten of the island countries had more than $50 \%$ of the population being overweight or obese, and $40 \%$ of the population in the region was diagnosed with a non-communicable disease (i.e. cardiovascular disease, diabetes, and hypertension $)^{39}$. A significant shift away from traditional foods and towards imported, caloriedense foods was considered a major contributor to the obesity epidemic ${ }^{39}$. In Tonga, it was estimated that over $70 \%$ of adults were overweight or obese, and $19.0 \%$ of the population was diagnosed with type II diabetes in $2012^{40}$. The prevalence of overweight/ obesity observed among only adolescents aged 12-15 years accentuated the extent of the obesity epidemic in Tonga. Bahrain and Brunei had one of the highest prevalence of overweight/obese adolescents in their respective region ${ }^{41,42}$. In Bahrain, a rapid shift from traditional foods to those rich in fats and calories was a major contributing factor ${ }^{43}$, but no study has comprehensively examined factors contributing to the overweight/obesity epidemic among children and adolescents in Brunei.

Adolescents in Syria (14.8\%) had the highest prevalence of tobacco use among all countries examined. Syria's tobacco epidemic only came to light when data on tobacco use based on convenience samples and then on nationally-representative samples emerged in the early $2000 \mathrm{~s}^{44}$. Data collected by the Syrian Center for Tobacco Studies (SCTS) revealed that $51.4 \%$ adult men and $11.5 \%$ adult women smoked cigarettes daily, while $20.2 \%$ adult men and $4.8 \%$ adult women engaged in waterpipe tobacco use ${ }^{44}$. The lack of comprehensive tobacco-control policies or resources for cessation and counseling is compounded by political turmoil, highlighting the need for expeditious efforts to resolve this public health crisis 
in Syria. In 2015, 14.8\% of children aged 13-15 years engaged in tobacco use in Guyana ${ }^{45}$, an increase from $11.3 \%$ (12-15 years) in 2009 found in the present study. Guyana's National Tobacco Act, celebrated as the most comprehensive tobacco control law in the nation, was enacted in 2017, and the effectiveness of the Act in reducing smoking prevalence is to be assessed in the coming years ${ }^{45}$.

The current study did not find a consistent association between BMI categories and tobacco use among adolescents across 23 countries. In the few countries where the association was evident, underweight status was associated with lower odds of tobacco use, but the association between overweight/ obesity and tobacco use went in both directions. In Uganda, Namibia, and Algeria, adolescent tobacco users had greater odds of being overweight or obese, whereas in Indonesia and Malaysia, adolescent tobacco users had lower odds of being overweight or obese. Adolescent tobacco users in Indonesia, Suriname, and French Polynesia had lower odds of being underweight. The finding in Malaysian adolescents was consistent with that from another study utilizing the GSHS data, yet, no explanation for the association was provided ${ }^{46}$. In Indonesia, adolescent tobacco users had lower odds of being on both ends of the BMI categories. A longitudinal analysis of 9000 men aged 15-55 years in Indonesia revealed that, smoking was related to weight loss and lower BMI, yet, the size of the effect was too small ${ }^{47}$. No comparable study was conducted to examine this association in the adolescent population in Indonesia.

These results were largely consistent with findings from several meta-analysis reviews ${ }^{10,48,49}$. In one metaanalysis review, findings from 55 studies revealed mixed evidence for an association between smoking and body weight among adolescents, with some studies reporting a positive association while other studies reporting no association ${ }^{10}$. The review found smoking was more evidently correlated with some general weight concerns among female adolescents, but no clear gender patterns were found in the association between smoking and body weight ${ }^{10}$. According to some researchers, a positive association between tobacco use and body weight was mainly attributed to the following factors: some overweight adolescents engaged in tobacco use to control their weight; smoking and obesity-related behaviors such as physical inactivity and sedentary behavior tend to cluster ${ }^{10}$. Besides the above factors commonly observed among adolescents in western countries, another important factor of smoking participation or continuation among adolescents from low- and middle-income countries was cigarette affordability ${ }^{50}$. Compared with adults, adolescents especially those from low-income households tend to be more sensitive to increases in tobacco prices ${ }^{51}$. Furthermore, underweight status or overweight/obesity were both positively associated with household wealth in low- and middle-income countries $^{47,52,53}$. As a result, it is possible that in these countries, underweight adolescents might be less financially capable and overweight/obese adolescents might be more financially capable to afford tobacco products. However, such proposed associations were not consistently observed across all countries in the current study, indicating the need for more research on this topic in the target population.

\section{Limitations}

This study has several limitations. First, most of the variables used in this study were derived from selfreport data, which could be subject to recall bias. However, the GSHS uses standardized survey items across participating countries since its inception in 2003, many researchers have utilized data from the GSHS and examined validity of its items. Nonetheless, research using both objectively-measured and self-reported data is needed. Second, due to the proportion of missing data or the absence of questions assessing variables used in the current analysis, data from many countries were excluded from this study. Inclusion of data from more countries may facilitate a more complete view of the association between BMI categories and tobacco use. Third, due to the lack of studies on the BMI-categories-tobacco-use association in the adolescent population in the majority of lowand middle-income countries, we can only speculate on the probable mechanisms.

\section{CONCLUSIONS}

This study aimed to draw attention to the prevalence of BMI categories and their association with tobacco use in the adolescent population worldwide. Considerable between-country heterogeneities were found, with a significant association observed in only a few countries. In countries where a significant association 
was observed, tobacco use was associated with lower odds of being underweight, yet, its association with overweight/obesity went in both directions. Taken together, these findings imply that the association between tobacco use and BMI categories is likely to be different among adolescents versus adults. That is, the inverse association between body weight and tobacco use commonly observed in adults may not apply to adolescents, thus, associating tobacco use with being thin may be more myth than fact, and such messages should be emphasized in tobacco prevention programs targeting adolescents. Nonetheless, a more complete understanding of this association among adolescents may benefit from studies that are prospective in design and clarify stages of smoking and anthropometric measurements.

\section{REFERENCES}

1. World Health Organization. Noncommunicable diseases. June 1, 2018. Accessed November 7, 2020. https://www.who.int/news-room/fact-sheets/detail/ noncommunicable-diseases

2. World Health Organization. 2018 Global Progress Report on Implementation of the WHO Framework Convention on Tobacco Control. World Health Organization; 2018. https://www.who.int/fctc/reporting/WHO-FCTC-2018_ global_progress_report.pdf?ua=1

3. Anderson C, Becher H, Winkler V. Tobacco Control Progress in Low and Middle Income Countries in Comparison to High Income Countries. Int J Environ Res Public Health. 2016;13:1039. doi:10.3390/ijerph13101039

4. Gilmore AB, Fooks G, Drope J, Bialous SA, Jackson RR. Exposing and addressing tobacco industry conduct in low-income and middle-income countries. Lancet. 2015;385:1029-1043. doi:10.1016/S0140-6736(15)60312-9

5. Filozof C, Fernández Pinilla MC, Fernández-Cruz A. Smoking cessation and weight gain. Obes Rev. 2004;5(2):95-103. doi:10.1111/j.1467-789X.2004.00131.x

6. Rupprecht LE, Donny EC, Sved AF. Obese Smokers as a Potential Subpopulation of Risk in Tobacco Reduction Policy. Yale J Biol Med. 2015;88:289-294. Accessed November 28, 2020. https://www.ncbi.nlm.nih.gov/pmc/ articles/PMC4553649/

7. Yoon J, Bernell SL. Link Between Perceived Body Weight and Smoking Behavior Among Adolescents. Nicotine Tob Res. 2016;18:2138-2144. doi:10.1093/ntr/ntw116

8. Fang M. Association Between Adolescent Body Mass Index and Adulthood Smoking. Nicotine Tob Res. 2019;21:1629-1635. doi:10.1093/ntr/nty183

9. Centers for Disease Control and Prevention - Office on Smoking and Health. Preventing tobacco use among youth and young adults: A report of the Surgeon General.
Centers for Disease Control and Prevention - Office on Smoking and Health; 2012. Accessed November 28, 2020. https://www.cdc.gov/tobacco/data_statistics/sgr/2012/ consumer_booklet/pdfs/consumer.pdf

10. Potter B, Pederson L, Chan S, Aubut JA, Koval J. Does a relationship exist between body weight, concerns about weight, and smoking among adolescents? An integration of the literature with an emphasis on gender. Nicotine Tob Res. 2004:6:397-425. doi:10.1080/14622200410001696529

11. De Leon E, Smith KC, Cohen JE. Dependence measures for non-cigarette tobacco products within the context of the global epidemic: a systematic review. Tob Control. 2014;23:197-203. doi:10.1136/tobaccocontrol-2012-050641

12. Ayo-Yusuf OA, Burns DM. The complexity of 'harm reduction' with smokeless tobacco as an approach to tobacco control in low-income and middleincome countries. Tob Control. 2012;21:245-251. doi:10.1136/tobaccocontrol-2011-050367

13. de Onis M, Lobstein T. Defining obesity risk status in the general childhood population: Which cut-offs should we use? Int J Pediatr Obes. 2010;5:458-460. doi:10.3109/17477161003615583

14. Friedemann C, Heneghan C, Mahtani K, Thompson M, Perera R, Ward AM. Cardiovascular disease risk in healthy children and its association with body mass index: systematic review and meta-analysis. BMJ. 2012;345:e4759. doi:10.1136/bmj.e4759

15. Martin-Calvo N, Moreno-Galarraga L, Martinez-Gonzalez M. Association between Body Mass Index, Waist-toHeight Ratio and Adiposity in Children: A Systematic Review and Meta-Analysis. Nutrients. 2016;8:512. doi:10.3390/nu8080512

16. Lipsky LM, Haynie DL, Hill C, et al. Accuracy of SelfReported Height, Weight, and BMI Over Time in Emerging Adults. Am J Prev Med. 2019;56:860-868. doi:10.1016/j.amepre.2019.01.004

17. Kuczmarski RJ, Ogden CL, Guo SS, et al. 2000 CDC Growth Charts for the United States: methods and development. Vital Health Stat 11. 2002;(246):1-190. Accessed November 28, 2020. https://www.cdc.gov/ nchs/data/series/sr_11/sr11_246.pdf

18. de Onis M, Onyango AW, Borghi E, Siyam A, Nishida C, Siekmann J. Development of a WHO growth reference for school-aged children and adolescents. Bull World Health Organ. 2007;85:660-667. Accessed November 28, 2020. http://www.who.int/bulletin/volumes/85/9/07-043497. pdf

19. Grummer-Strawn LM, Reinold C, Krebs NF. Use of World Health Organization and CDC growth charts for children aged 0-59 months in the United States. MMWR Recomm Rep. 2010;59(RR-9):1-15. Accessed November 28, 2020. http://www.ncbi.nlm.nih.gov/pubmed/20829749

20. Bosman L, Herselman MG, Kruger HS, Labadarios D. Secondary Analysis of Anthropometric Data from a South African National Food Consumption Survey, Using Different 
Growth Reference Standards. Matern Child Health J. 2011;15:1372-1380. doi:10.1007/s10995-010-0685-5

21. de Onis M, Garza C, Onyango AW, Borghi E. Comparison of the WHO Child Growth Standards and the CDC 2000 Growth Charts. J Nutr. 2007;137(1):144-148. doi:10.1093/jn/137.1.144

22. El Mouzan MI, Foster PJ, Al Herbish AS, et al. Prevalence of overweight and obesity in Saudi children and adolescents. Ann Saudi Med. 2010;30:203-208. doi:10.4103/0256-4947.62833

23. Fetuga MB, Ogunlesi TA, Adekanmbi AF, Alabi AD. Growth pattern of schoolchildren in Sagamu, Nigeria using the CDC standards and 2007 WHO standards. Indian Pediatr. 2011;48:523-528. doi:10.1007/s13312-011-0094-x

24. Borade A, Bhide G, Kadam G, Dhongade R. Study of blood pressure and blood sugar levels in adolescence and comparison with body mass index. Indian J Med Sci. 2011;65:297. doi:10.4103/0019-5359.107391

25. Centers for Disease Control and Prevention, World Health Organization. 2013 GSHS Data User's Guide. Updated September 17, 2013. Accessed November 28, 2020. https://www.cdc.gov/gshs/background/pdf/gshs-datausers-guide.pdf

26. Wang Q. Tobacco use and sleep loss over worry among adolescents aged 12-15 years: A population-based study of 38 countries. J Glob Health. 2020;10(2). doi:10.7189/jogh.10.020427

27. Lange S, Koyanagi A, Rehm J, Roerecke M, Carvalho AF. Association of Tobacco Use and Exposure to Secondhand Smoke With Suicide Attempts Among Adolescents: Findings From 33 Countries. Nicotine Tob Res. 2020;22:1322-1329. doi:10.1093/ntr/ntz172/5561377

28. World Health Organization. Fruit and Vegetables for Health: Report of a Joint FAO/WHO Workshop, 1-3 September 2004, Kobe, Japan. World Health Organization; 2005. Accessed November 28, 2020. https://apps.who. int/iris/bitstream/handle/10665/43143/9241592818_ eng.pdf?sequence $=1 \&$ cisAllowed $=y$

29. Dong Y, Peng CYJ. Principled missing data methods for researchers. SpringerPlus. 2013;2. doi:10.1186/2193-1801-2-222

30. Gorelick MH. Bias arising from missing data in predictive models. J Clin Epidemiol. 2006;59(10):1115-1123. doi:10.1016/j.jclinepi.2004.11.029

31. Higgins JPT. Measuring inconsistency in meta-analyses. BMJ. 2003;327:557-560. doi:10.1136/bmj.327.7414.557

32. Hirani SAA. Malnutrition in young Pakistani children. J Ayub Med Coll Abbottabad. 2012;24(2):150-153. Accessed November 28, 2020. https://jamc.ayubmed. edu.pk/jamc/index.php/jamc/article/view/2220/1041

33. Adebisi YA, Ibrahim K, Lucero-Prisno DE, et al. Prevalence and Socio-economic Impacts of Malnutrition Among Children in Uganda. Nutr Metab Insights. 2019;12. doi:10.1177/1178638819887398
34. Christoph MJ, Grigsby-Toussaint DS, Baingana R, Ntambi JM. Physical Activity, Sleep, and BMI Percentile in Rural and Urban Ugandan Youth. Ann Glob Health. 2017;83:311-319. doi:10.1016/j.aogh.2017.04.005

35. Comandini O, Cabras S, Ssensamba JT, et al. Nutritional status of Ugandan school-children: The effect of age imprecision. Am J Phys Anthropol. 2019;170:88-97. doi:10.1002/ajpa.23895

36. Caleyachetty R, Rudnicka AR, Echouffo-Tcheugui JB, Siegel KR, Richards N, Whincup PH. Prevalence of overweight, obesity and thinness in 9-10 year old children in Mauritius. Global Health. 2012;8:28. doi:10.1186/1744-8603-8-28

37. Maehara M, Rah JH, Roshita A, Suryantan J, Rachmadewi A, Izwardy D. Patterns and risk factors of double burden of malnutrition among adolescent girls and boys in Indonesia. PLoS One. 2019;14:e0221273. doi:10.1371/journal.pone.0221273

38. Amoussou Lokossou YU, Azandjèmè C, Ayuk BT, Mbhenyane $\mathrm{X}$. The presence of the double burden of malnutrition in children and their mothers in GrandPopo, Benin. Nutr Health. 2020;260106020962787. doi:10.1177/0260106020962787

39. Pacific islanders pay heavy price for abandoning traditional diet. Bull World Health Organ. 2010;88:484485. doi:10.2471/BLT.10.010710

40. Lin S, Hufanga S, Linhart C, et al. Diabetes and Obesity Trends in Tonga Over 40 Years. Asia Pac J Public Health. 2016;28:475-485. doi:10.1177/1010539516645156

41. Mirmiran P, Sherafat-Kazemzadeh R, Jalali-Farahani S, Azizi F. Childhood obesity in the Middle East: a review. East Mediterr Health J. 2010;16:1009-1017. Accessed November 28, 2020. https://applications.emro.who.int/ emhj/V16/09/16_9_2010_1009_1017.pdf

42. Pengpid S, Peltzer K. Overweight, Obesity and Associated Factors Among 13-15 years Old Students in the Association of Southeast Asian Nations Member Countries, 2007-2014. Southeast Asian J Trop Med Public Health. 2016;47(2):250-262. Accessed November 28, 2020. https://www.tm.mahidol.ac.th/ seameo/2016-47-2/12-681213-250.pdf

43. Musaiger AO. Overweight and obesity in the Eastern Mediterranean Region: can we control it? East Mediterr Health J. 2004;10(6):789-793. Accessed November 28, 2020. https://applications.emro.who.int/ emhj/1006/10_6_2004_789_793.pdf

44. Ward KD, Eissenberg T, Rastam S, et al. The tobacco epidemic in Syria. Tob Control. 2006;15 Suppl 1:i24-i29. doi:10.1136/tc.2005.014860

45. Pan American Health Organization, World Health Organization - Regional Office for the Americas. Guyana's Tobacco Control Act: One year on. Accessed November 11, 2020. https://www.paho.org/hq/index.php?option=com _ content\&view $=$ article\&id $=14494$ : guyanas - tobaccocontrol-act-one-year-on\&Itemid=135\&lang=en 
46. Tan AKG, Yen ST, Fang X, Chiang FS. Body weight and physical activity of adolescents in Malaysia. Int Health. 2019;11:150-158. doi:10.1093/inthealth/ihy072

47. Sohn K. The effects of smoking on obesity: evidence from Indonesian panel data. Tob Induc Dis. 2015;13(November):1-8. doi:10.1186/s12971-015-0064-5

48. French SA, Jeffery RW. Weight concerns and smoking: A literature review. Ann Behav Med. 1995;17:234-244. doi:10.1007/BF02903918

49. Chao AM, Wadden TA, Ashare RL, Loughead J, Schmidt HD. Tobacco Smoking, Eating Behaviors, and Body Weight: a Review. Curr Addict Rep. 2019;6:191-199. doi:10.1007/s40429-019-00253-3

50. Kostova D, Ross H, Blecher E, Markowitz S. Is youth smoking responsive to cigarette prices? Evidence from low- and middle-income countries. Tob Control. 2011;20:419-424. doi:10.1136/tc.2010.038786

51. Forster JL, Widome R, Bernat DH. Policy interventions and surveillance as strategies to prevent tobacco use in adolescents and young adults. Am J Prev Med. 2007;33:S335-S339. doi:10.1016/j.amepre.2007.09.014

52. Reyes Matos U, Mesenburg MA, Victora CG. Socioeconomic inequalities in the prevalence of underweight, overweight, and obesity among women aged 20-49 in low- and middleincome countries. Int J Obes (Lond). 2020;44:609-616. doi:10.1038/s41366-019-0503-0

53. Li Z, Kim R, Vollmer S, Subramanian SV. Factors Associated With Child Stunting, Wasting, and Underweight in 35 Low- and Middle-Income Countries. JAMA Netw Open. 2020;3(4). doi:10.1001/jamanetworkopen.2020.3386

\section{CONFLICTS OF INTEREST}

The author has completed and submitted an ICMJE form for disclosure of potential conflicts of interest. The author declares that she has no competing interests, financial or otherwise, related to the current work. 0 . Wang reports that she received from Shanghai Jiao Tong University School of Medicine, a grant (No. 19X100040041).

\section{FUNDING}

Shanghai Jiao Tong University School of Medicine.

ETHICAL APPROVAL AND INFORMED CONSENT

All GSHS surveys were approved by the Ministry of Education and an institutional review board or ethics committee in each participating country. Student participation was voluntary and anonymous. Verbal or written informed consent was obtained from students, their parents and schools prior to survey administration.

PROVENANCE AND PEER REVIEW

Not commissioned; externally peer reviewed. 